\title{
Chromosomal Loss
}

National Cancer Institute

\section{Source}

National Cancer Institute. Chromosomal Loss. NCI Thesaurus. Code C36315.

Loss of an entire chromosome or chromosome arm. 